\title{
KIRIM KARAYLARI HAKKINDA KULLANILAN BAZI KAVRAM VE ANLAM YANLIŞLIKLARI ÜZERINE
}

\author{
ON THE WRONG USE OF SOME CONCEPTS AND \\ SEMANTIC MISTAKES ABOUT CRIMEAN KARAIS
}

\author{
О НЕКОТОРЫХ КОНЦЕПЦИЯХ И ЗНАЧЕНИИ СЛОВ \\ ИСПОЛЬЗУЕМЫХ ДЛЯ КРЫМСКИХ КАРАИМОВ
}

\author{
Erdoğan ALTINKAYNAK*
}

\section{ÖZ}

Kırım Karaylarının kendi iddiaları ve tarihi belgelerin doğrulamasıyla Hazar Kağanlığının bakiyeleri olduğu ortadadır. Karaist mezhebine mensup çok sayıda halk vardır. Ancak bunlardan Türk soylu olanların ortak adı Kırım Karaydır. Yerleşim yeri veya anayurtları Kırım'dır. Kırım'ın Çiftkale kale şehri onların merkezidir. Çeşitli dönemlerde Litvanya ve Kafkasya'ya kafileler halinde göç etmişlerdir.

Kendilerine ait kalenin adı oluşumundan kaynaklanmaktadır. İki kale demektir. Dilleri Kırım Tatar Türkçesine çok yakındır.

Kutsal meşe ağaçlarının bulunduğu Balta Tiymez mezarlığ Avrupa'nın yaşayan en eski mezarlığıdır. Bu mezarlık ağaç kültünün varlığının en önemli delillerindendir. Kırım Karay ailelerinden her birinin bu mezarlıkta bir meşe ağacı vardır. Bu ağaca gelecek zarar bütün soya gelmiş kötülük olarak kabul edilir. Mezar koruyucusu veya bekçisine "Gabay" denilir.

Kırım Karayları arasında akraba evliliği yoktur. Yalnız başına bu bile onları diğer Musevi topluluklarından ayırmaya yeter. Etle süt ürünlerini birlikte kullanmaları, kenasa adı verilen ibadet hanelerine, kuzu derisinden yapılma siyah bir kalpakla girmeleri, tora adı verilen kıbleye arkalarını dönmeden dışarı çıkmaları kendilerine mahsus davranış biçimleridir.

Bu yazımızda, artık yok olmaya yüz tutmuş bir Türk boyu olan Kırım Karaylar ile ilgili kavramlar ve algılamada yanlışlıklar üzerine durulacaktır. Kırım Karayların Kırım'dan başka ülkelere göçü, diğer Musevi dinlilerden ayrılan noktaları, kökenleri, tarih sahnesinde görünmeleri, meslekleri, yerleşim alanları, bazı önemli şahsiyetleri, mezheplerinin ortaya çıkışı anlatılmaktadır.

Anahtar Kelimeler: Kırım Karay, göç, Hazar Kağanlığı, Karaizm, Annan bin David, Kale.

\footnotetext{
*Prof. Dr., Ardahan Üniversitesi TDE Bölümü. ARDAHAN

( erdoganaltinkaynak@ardahan.edu.tr)

DOI: 10.17498/kdeniz.399958
} 


\section{ABSTRACT}

In line with the Crimean Karai allegations and the support of historical documents, it is obvious that they are the descendants of Khazar Khanate. There are many communities who are the members of Karais Sect. However, the common name of Turkic origins are Crimean Karais. Their main settlement and homeland is Crimea. Çiftkale city in Crimea is their settlement center. They are known to have migrated in masses to Lithuania and Caucasia in various periods.

The name of their castle is derived from its type of construction. It means two castles. Their language is close to Crimean Tatar Turkish.

Balta Tiymez Cemetery, where there are sacred oak trees, is the oldest cemeter still active in Europa. It is the greatest proof of the existence of tree cult. Every Crimean Karai family has a tree in the cemetery. Any harm to be done to the tree is regarded a harm committed against all the generations of the family. The guard or protector of the cemetery is called "Gabay".

There is no consanguineous marriage among Crimean Karais. That sole fact is adequate to make them different from other Jewish communities. They have some behavioral patterns confined to their cultures such as consuming meat and dairy products together, entering their pray places called "kenasa" with a black hood made of lamb skin, and leaving the place without turning their backs to the qibla, which they call "tora".

In this article, we will focus on misuse and misundertandings of some concepts about Crimean Karais, who are a Turkic tribe about to disappear. Their migration from Crimea to other countries, the differences they have from other Jewish communities, their origins, their appearance in history, frofessions, settlements, important figures and the appearance of their sects will also be discussed.

Key words: Crimean Karai, Migration, Khazar Khanate, Karaism, Annan bin David (Annan, son of David), Castle.

\section{АННОТАЦИЯ}

Кладбище Балта Тиймез с священными дубами является одним из старинных кладбищ Европы. Это кладбище является важным доказательством наличия культа дерева. В каждой караимской семье Крыма, имеется на кладбище дуб. Дуб сажался для того, чтобы любой вред, который мог прийти в семью, принимало на себе это дерево. Сторожа кладбища называли «Габаем». У крымских караимов нет заключения браков между родственниками. Достаточно этого признака, который отличает их от остального еврейского общества. Одновременное использование мяса и молочных продуктов, название кенаса для отправления религиозных обрядов, ношение шапок из шкуры чёрных ягнят, запрет поворачиваться к священной Торе спиной выходе из помещения определяют их отличительные черты.

В настоящее время крымские караимы находятся на стадии исчезновения что и послужило поводом остановится на терминологии и 
ошибочной трактовки значений слов крымских караимов. В статье будут затронуты такие темы как: появление караимов на исторической арене и их происхождение, переселение из Крыма в другие страны, прикладные искусства, сферы деятельности, некоторые известные личности, появление сект и отличительные черты религии караимов от других еврейских религий.

Ключевые слова: крымские караимы, переселение, хазарское (каспийское) ханство, караизм, Аннан бин Давид, крепость.

Kırım Karayları, Hazar Türklerinin bakiyeleri olarak bugünkü Ukrayna'nın Kırım Özerk Cumhuriyeti ve Galiç Bölgesinde; Litvanya'nın Vilnus bölgesinde ve dağınık olarak da Fransa, Azerbaycan (Kafkasya), Türkiye, Rusya, Polonya gibi ülkelerde yaşamakta olan bir Türk halkıdır. Anayurtları Kırım'dır. Günümüzde nüfusları oldukça azalan Kırım Karayları diğer bölgelere ve coğrafyalara buradan dağılmışlardır.

Karaizm mezhebini sadece Türk asıllılar benimsememişlerdir. Karay mezhebini benimsemiş Hintli, Afganistanlı, Polonyalı, Kafkasyalı karaistler de vardır. Dünyanın değişik coğrafyalarında ve milletleri arasında da bu mezhebi seçenler vardır. Diğer Karaylarından ayırmak için kendilerine Kırım Karay diye adlandırmaktadırlar.

Kırım - Trakay(Vilnus) - Galiç diye üç ağzı olan Kırım Karay Türkçesini günümüzde kullanan ve bilen yok gibidir. Uzun süre Rusça'nın etki alanında kalmaları onların dillerini unutmalarına sebep olmuştur. Toplum olarak da her geçen gün azalmaları, onların müzelik halklar sınıfına girmelerine sebep olmuştur.

Her ne kadar Kırım Karayları Hazar Kağanlığının bakiyeleri olsa da onların Kırım'a gelip yerleşmeleri, Firkoviç ve Firkoviç’ten sonra değişik bilim adamlarının, Kırım Karaylarının kutsal mekânı, Balta - Tiymez Ormanı içindeki mezarlıkta yaptıkları araştırmalar neticesinde elde edilen bilgilere göre, milattan öncelere dayandığı ortaya çıkmıştır (Altınkaynak, 2004, 34-38).

Kırım Karaylarından bazı gruplar değişik tarihlerde ve nedenlerle Kırım'dan göç ederek başka yerlere yerleşmişlerdir. Bizanslılar döneminde Bizans - Hazar ilişkileri nedeniyle II. Jüstinien ile evlenen Hazar Prensesi Thedora ve Hazar Kağanlığı'nın prensesi Çiçek Hanım ile Bizans İmparatoru V. Konstantin ile evlenmesiyle gerçekleşmiş ve Karaylar İstanbul'un Karaköy (Karayköy) semtini kurmuşlardır (Anzerlioğlu, 2003, 30-31). İlk göç 1246 tarihli Galiç göçüdür. 1395 tarihinde bir grup Kırım Karay Kafkasya'ya göç etmişlerdir. Şimdiki Litvanya'da yaşayan Kırım Karaylar 1396 -1398 y1llarında 400 aile olarak Prens Vivot tarafından Kırım'dan davet edilmiş ve yerleştirilmişlerdir. Burada çiftçilik, bağbahçe işleri ve nakliyecilik işleri ile uğraşmışlardır (Altınkaynak, 2006,3). Mısır'da bulunan Karayların buraya nasıl ve ne zaman gittikleri hakkında bir bilgimiz yoktur.

Kırım Karaylarının değişik prenslikler veya devletler tarafından topraklarına davet edilmeleri ve onlara bir takım imtiyazların tanınmasını şöyle açıklayabiliriz. Kırım Karaylarının Kale muhafazalarında tecrübeli ve iyi yetişmiş birer askerdir. Barış zamanlarında herkesle rahatça ve hoşgörü içinde diyalog kurabilen ve üretimi 
iyi bilen yetenekli insanlardır. Her şeyden önemlisi de ihanet etmeyi bilmeyen sadık yurttaşlardır. Nitekim Bizans İmparatorluğu döneminde İstanbul'un bazı kapılarının muhafızlığını Hazar Kağanlığından gelen askerler yapmaktadır. Kırım Hanlığının önemli işlerini Kırım Karayları yapmaktadır. Stratejik tutukluların Çift Kalede muhafazası da Kırım Karaylarına bırakılmıştır. Çarlık Rusyası ordularında Bazı Kırım Karay Türkleri önemli mevkilere gelmiş, Çar Nikola da Bahçesaray'ı, Çift Kale'yi ve Kezleve'yi ziyaret ederek Çift Kale'deki Kırım Karay Misafirhanesinde ikamet etmiştir. Bu da onlara karşı duyulan bir güvenin ifadesidir. Ayrıca Seraya Şapşal'ın Atatürk ve İran Şahı ile kurduğu dostluklar ve devlet hizmetinde bulunması dikkate şayandır.

Kırım Karayları, Karay Mezhebinden olan Türk soylu halktır. Karay Mezhebi Annan Ben David tarafindan kurulmuştur (Kuzgun, 1993, 93). Ancak, Kırım Karaylarının dışında da bu mezhebe inanan insanlar vardır. Kırım Karayları kendilerini onlardan ayırmak için onlara sadece Karay adını verirler. Bugün kendilerini tanıtırken de Rusça olarak "mı Karaimu Türkov" (Biz Karay Türküyüz) derler. Yani başka milletlerden ve ırklardan da Karay mezhebini seçenler vardır. Mesela Slav, Sami, Germen, Latin, Hintli, Çinli vs milletlerden Karay mezhebini seçenler... Fakat Kırım Karayları Türk'tür.

Bazı araştırmacı ve bilim adamları bilerek veya bilmeyerek Kırım Karay Türklerini "Yahudi" veya "Yahudi Türkler" diye adlandırmaktadır. Kırım Karayları ise bunu kendilerine yapılmış bir hakaret olarak görmektedir. Esasında Yahudilik Museviliğin bir yorumudur. Yani bir mezhebidir ve Yahudilik ile İsrailoğulları birlikte anılırlar.

Çarlık Rusyası da Tıpkı Osmanlılar gibi dine dayalı bir devletti. Bu yüzden vatandaşlarını da dinlerine göre kaydederdi. Yani hangi ırktan olduğu değil hangi dinden olduğu nüfuslarına kaydedilirdi. Çarlık Rusyasında Yahudilerin kimliğine 'Yahudi' Karayların kimliğine de 'Karay' yazılmaktaydı. Bunun nedeni de Firkoviç ve Seraya Şapşal'ın, Çarlık'a müracaat ederek, kendilerinin, yani Kırım Karaylarının Hz. İsa'yı çarmıha geren Yahudilerden olmadığını, kendilerinin Hazar Kağanlığının varisleri Türkler olduğunu iddia ve ispat etmeleriydi. Bu sayede Çarlık Rusyasında Kırım Karayları Ruslara tanınan hakların tamamından yararlanmıştır. Hâlbuki Yahudiler, diğer Hıristiyan ülkelerde olduğu gibi, içinde yaşadıkları ülkenin insanlarına tanınan haklardan yararlanamıyorlar ve fazladan vergi vermek zorunda kaliyorlardi.

Talmudizm ve Karaimizm arasında her zaman anlaşmasızlıklar olmuştur. M.S. VIII. Asırdan Karay dininin kurucusu Anan bin David devrinden başlayarak iki din arasında çelişkiler bitmemiştir. Din meseleleri nedeniyle iki topluluk arasında kız alış verişi, evlilik kesinlikle söz konusu değildi. Talmundizmde evlilik bağı olduğunda bile onların dinini kabul etmeleri yasaktı. Talmuda inananlar Karayları "dalal" (dinden sapmış) olarak saymışlardı. Karaylara göre Yahudiler gerçek dinin bozucuları olarak görüldüklerinden kendilerini Yahudi diye adlandırılmalarına şiddetle karşı çıkmaktadırlar (Altınkaynak, 2006,4). 
Kırım Karaylarının Yahudilerden inanç açısından farklılığını Evliya Çelebi de zikretmektedir. Evliya Çelebiye göre Karay Cemaati Yahudilerin Kızılbaşlarıdır. Diğer Yahudiler bunları sevmezler. Bunlar İsrailli Musevilerdir. Tevrat ve Zebur okurlar ve cıfit lisanı bilmezler. Tatarca konuşurlar (Seyahatname, 1980,377). Evliya Çelebinin bu yorumlarına pek çok noktadan katılmamız mümkün değildir. Öyle sanıyoruz ki bunlar derinlemesine incelenmeden, önyargılı olarak söylenen sözlerdir veya pek çok şekilde olduğu gibi duyduklarını yazmış olabilir.

Evliya Çelebi sadece Çift - Kale'deki Kırım Karaylarından değil, Çift Kale'ye yakın mesafede Mangupkale'deki ve Karasubazar'daki Karaylardan da bahsetmektedir (Seyahatname, 1980, 374-441).

İslam öncesi Türklerin tamamında ve günümüzde de Kıpçak boyları arasında olduğu gibi Kırım Karaylarında da akraba evliliği yoktur. Eşlerden birisi öldüğü takdirde başkaları ile evlenebilirler. Yahudilerde ise eşlerden biri öldüğ̈ takdirde başka birisi ile evlenmek yoktur. Erkeklerin iki eşli olması da ancak Din Kurulunun kararı ile mümkündür. Yani çok özel şartlar oluşmadan çok evlilik de yoktur.

Kırım Karaylarında çocuk, diğer Türk halklarında olduğu gibi babanın sulbüne tabidir. Yahudilerde ise çocuklar annenin sulbüne tabidir. Yani Yahudiler anaerkil, Kırım Karayları ataerkil aile tipindedirler.

Kırım Karaylarının ölüm adetleri ve doğum adetleri de Yahudilerinkinden farklıdır. Kırım Karayların geçiş dönemlerinde geçirilen sembolik ritüeller atalar dinine ait bakiyeler içermektedir (Altınkaynak, 2006,12). Özellikle karabiber katılarak karılan "kara helva" çok ilginçtir. Bu helva, acıyı paylaşmanın ifadesidir.

Kırım Karaylarının giyim kuşamları da Yahudilerinkine benzemez. Kırım'daki diğer Türk halkları ile ortaktır. İbadet merkezinde başı açık olmak hem Yahudilerde ve hem de Karaylarda uygun görülmemektedir. Kırım Karaylarının ibadethanelerinde başlarına koydukları kuzu derisinden yapılan kalpak, Yahudilerde ise takkeye benzeyen bir başlık vardır.

Kırım Karaylarının din özelliği atalar dini ile Hz. Musa'nın "on emir" inin sentezinden ibarettir. Yahudilik ile benzemeyen çok yönü vardır. İbadet hanelerinin yönü (Kırım Karaylarınınki kuzey - güney yönündedir), adı (Kırım Karaylarınınki kenasadır) ve şekli (Kırım Karaylarınınki daha çok iki katlı binaya benzer, girişi kuzeydendir. Güneyde “tör" adı verilen mihrap bulunur ve Kırım Karayları tör'e arkalarını dönerek kapıdan çıkmazlar) değişiktir. İbadet şekilleri de farklıdır. Bu durumu en iyi şekilde Kırım Özek Cumhuriyetinin şehirlerinden olan Kezleve'de görebilirsiniz (Ruslar buraya Yevpotarya adını vermişlerdir). Kezleve merkezde sinagok ile kenasanın arası yüz metre kadardır.

Kırım Karayları için İosafat vadisinde bulunan Çift Kale ve Balta - Tiymez ormanı kutsal mekândır. Buradaki mezarlık ve Kutsal meşe ağaçları önemlidir. Bu meşe ağaçlarının kutsallığı tapınan bir obje olması ile alakalı değildir. Her ağaç bir boyun kökünü temsil eder ve bu ağaç etrafinda yapılan duaların kabul olacağına inanılır. Her sene bu meşe ağaçlarının ve mezarlığın olduğu orman ziyaret edilir, bakımı - onarımı yapılır. Kırım'da olduğumuz süre içinde burası ile ilgili bir proje hazırlamış ve TiKA'ya sunmuştuk. Bu mezarlıkta "yolcutaş" adı verilen anıt 
mezarlar da vardır. Yolcutaşlar, Kırım'dan uzakta ölenlerin anısına dikilmektedir. Bu kural herkes için geçerli değildir. Ancak Kırım Karay halkına büyük hizmetleri geçmiş insanlar içindir. Bu mezarları ziyaret, kitabelerinin üzerine küçük bir taş bırakılarak gerçekleştirilmektedir.

Kırım Karaylarında dini yönetimin başı aynı zamanda siyasi yönetimin de başıdır. Kendilerine han olarak seçtikleri son kişi ise Seraya Şapşal'dır. Hanedanlık Sovyet Rusyasında kaldırıldıktan sonra Şapşal'ın hanlığ 1 resmi olarak bitmiş ve fakat halk arasında manevi olarak devam etmiştir.

Almanların Kırım'1 işgal etmesiyle toplayıp yok ettikleri Musevilerin pek çoğu; yine Hazar Kağanlığı'nın bakiyelerinden olan ve XIX. Asrın sonlarında Türkiye'den gelen bir haham vasitası ile talmudist inanca geçirilen Kırımçak Türkleri olmuştur. Almanlar Kırımçaklara pek ilişmemiş ancak Almanların geri çekilmesiyle Kırım Karaylar da Stalin'in hışmına uğramış ve yurtlarından sürgün edilmişlerdir.

Kırım Karayları Çarlık Rusyası döneminde oldukça etkili yerlere gelmiş ve zenginleşmişlerdir. Mesela bütün Çarlık Rusyasının tütün tekelinin \% 70’i Kırım Karaylarının elindedir. Çarlık Rusyası'nın son başbakanı ve daha sonraları "çar" olarak ilan edilen Amiral Kolçak da bir Karay Türküdür. Çarlığın yıkılmasıyla pek çok Kırım Karay Türkü göç etmiş, bir kısmı Türkiye'ye ve buradan da Fransa ve Amerika'ya göç etmişlerdir. Fransa'ya göç edenlerden birisi de 1916 - 1917 yıllarında Trabzon'da, işgal ordularının subayı ve Trabzon belediye başkanlığı yapan Yakup Kefeli'dir.

Kırım Karaylarının mutfak kültürü de Yahudilerinkine benzemez. Yahudiler et ile birlikte süt ürünlerini yemezler. Hâlbuki Kırım Karaylarının en çok sevdiği yiyecek ayran ile şiş kebaptır.

Kırım Karayları çok eski bir Türk yurdu olan Kırım'ın en eski ve yerli halkıdır. Kırım Karaylarının Kırım Tatarları ile bağları sadece aynı milletin mensupları olmasından gelmektedir ve dilleri de bu yüzden birbirine benzer. Kırım Karayları ve Kırım Tatarları arasında yönetsel anlamda herhangi bir problem görülmemekle birlikte, bazı zamanlarda Kırım Hanları Kırım Karaylarından daha fazla vergi almak adına, Kırım Karaylarının Kutsal saydığı Meşe ağaçlarını yakmakla tehdit ettiği bilinmektedir. Yönetimde olduğu gibi halk arasında zaman zaman anlaşmazlıklar doğduğu ve bu anlaşmazlıkların birinde Şamoil Ağa'nın öldürüldüğü bilinmektedir. Meryem Dere'ye birleşen Kanlı Dere adını XVIII. Asırda Karay ileri gelenlerinden Şamoil Ağa'nın burada öldürülmesinden almıştır. Fakat Kırım Hanları ile Kırım Karayları arasında çok uzun süreli güven duygusu tahsis edildiği, Kırım Hanlarının darphanesini Kırım Karaylarının işlettiği ve Çift Kale'nin aynı zamanda Kırım Hanlarının hapishanesi görevini üstlendiği de bilinmelidir.

Türkiye'de Yahudiler, özellikle yaşlı kadınlar Osmanlı döneminde pekiyi konuşamazlar. Yahudiler de İspanyolca ve Fransızcayı daha çok kullanmaktaydılar. Tanzimatla birlikte bu durumu bizzat Yahudi din adamları değiştirmeye çalışmış ve Türkçe kullanılmasını ögütlemişlerdir (Ortaylı, 2008,88). 
Karayların dili Türkçedir. Ve onlar bu dili sonradan öğrenmiş değillerdir. Bilindiği gibi Yahudiler bulundukları coğrafyanın veya birlikte yaşadıkları toplumların dillerini öğrenir ve günlük hayatta da bunu kullanırlar (Ortayl, 2008,89). Bu nedenle Kırım Karayların Türkçeyi sonradan ve Kırım Tatarlarından öğrenmiş olabileceklerini ileri sürenler de vardır. Ancak, sonradan öğrenilen dillerin kullanımı esnasında aksan ortaya çıkar. Halbuki Kırım Karaylarının en eski belgelerinde bile bu aksan ile karşılaşmıyoruz. Balta - Tiymezdeki mezar taşlarından ve Kırım Karay Türkçesindeki bazı kelimelerden öğrendiğimize göre Kırım Tatarlarının Kırım'a gelmesinden çok daha önceleri Kırım Karaylarının Türkçe konuştukları kesindir. Bu durumu Hacı Seraya Şapşal da bir makalesinde örneklerle izah etmiştir (Szapszal, 1938,81-90).

Kırım Karaylarının Antropolojik özellikleri de Yahudilerinkine benzemez. Kırım Karaylarının antropolojik özellikleri Yahudilerinki gibi Sami ırkına değil Turani ırkına ait özellikler gösterir.

Kırım Karayların takvimi de Yahudilerinkinden farklıdır. Onlar dini kitapları dahil haftanın günlerini Türkçe olarak bilir ve söylerler. Sadece ibadet günü olan cumartesinin adı 'şabat' kelimesinin gün kelimesi eklenmesiyle meydana getirilen 'şabat künü' şeklinde söylenmektedir. Kırım Karay Takvimine 'Ulugata Sanavı' denmektedir ve 12 hayvanlı Türk takvimidir. Aylar 12 değil 13 adettir ve 13. aya 'artıksı ay' adı verilir ve tamamıyla Türkçedir. Bu durum Kırım Karay Türkçesinin mevcut üç dialektinde de (Galiç - Trakay - Kırım) aynıdır.

Kısacası Kırım Karayları Yahudi, değildir.

Kırım Karayları ile ilgili ikinci bir bilerek veya bilmeyerek yapılan yanlış vardır ki o da Çift - Kale adının yanlış kullanılışıdır.

Çift - Kale, Bahçesaray yakınlarındaki Meryem Dere'nin üst tarafında 3 tarafı uçurum bir tarafı da sık ormanlık alan üzerine kurulmuş çok eski bir yerleşim merkezidir. Bu kaleyi de Kırım Karayları kurmuştur. Meryem Derenin bir ucu Bahçesaray'a bir ucu da Balta - Tiymez ormanına çıkar. Bu vadide Meryem Ana Manastırı ve Müslüman Mezarlığı da vardır. Baba Mansur türbesi de bu mezarlıktadır ve fakat mezarlık tahrip edilmiş durumdadır. Vadi ile bitişen bir başka vadi veya dere yatağı vardır ki adı da Kanlı Dere'dir.

Çift - Kale'nin 3 kapısı vardır. Biyik Kapı Balta - Tiymez Ormanına ve mezarlığa giden yolda, doğu tarafındadır. Kiçik Kapı ise Meryem Dere'ye ve oradan da Bahçesaray'a giden dar yol için açılmıştır. Kiçik Kapı'dan kaleye girenler kobe adı verilen taşlara oyulmuş evlere ve kale duvarlarını aşmadan giremez "küllük" mevkii ile karşılaşır. Küllük mevkii askerlerin talim alanı ve aynı zamanda atların yaylım alanıdır. Biyik Kapı ve Kiçik Kapının dışında bir de Orta Kapı vardır ki bu kapı ile birbirine bağlanan iki kaleden ibarettir. Ortakapı'dan sonraki surlar daha sonra ilave edilmiştir. Bu kalelerden birisi eski, diğeri yenidir. Yeni Kısımda Firkoviç'in kaldığı konak vardır.

Bir başka anıt ise Caneke Hanum türbesidir. Türbe Kırım Hanı'nın kızı Caneke Hanum adına inşa edilmiştir. Kaledeki Camiden ise diğer bütün binalar gibi eser kalmamıştır. Az önce bahsettiğimiz konak şimdilerde restoran olarak hizmet 
vermektedir ve burayı Kırım Karayları işletmektedir. Tipik Türk Mimarisi ile muhteşem bir anıt gibi durmaktadır. Tavan süslemesi ahşap (ceviz) kaplamadır. Dış tarafinda firın ve kiler olarak kullanılan evden ayrı bir birim vardır.

Eski kale içinde iki kenasa vardır. Her sene on binlerce turist tarafindan ziyaret edilen bu kaleye Kırım Karayları ücret vermeden girer ve gezerler.

Kırım Karayları bu iki kaleyi çift kale diye adlandırmışlardır. Kırım Karay Türkçesinde çift kelimesi "çuft - çufut" diye söylenir. Yani Çuft-Kale veya Çufut Kale. İşte problem de buradan kaynaklanmaktadır. Kalenin adı "Cifitkale" yani (Yahudi Kalesi) diye adlandırılmaya ve literatüre yerleştirilmeye çalışılmaktadır. Kırım Karayları da buna şiddetle karşı çıkmaktadır.

Bir kere Kalenin adının yazılışına dikkat çekmek isteriz. Bilindiği gibi Kiril Alfabesinde 'c' sesi yoktur ve bu sesi karşlamak için 'dj' harfleri birleşik olarak kullanılmaktadır. Hâlbuki kalenin adının kiril alfabesi ile yazılışı 'ç' harfi iledir. Eğer bu kale cıfitkale diye yazılsa idi "ç" ile değil "dj” ile yazılırdı.

İkincisi, Kırım Karay toplumunun iddiasına göre bu kalede hiçbir zaman Yahudiler yaşamamıştır.

Arap alfabesinde de 'ç' sesi yoktur. Arap Alfabesi kullanan Osmanlılar ve Kırım Tatarları bu sesi karşılamak için c harfinin noktasını artırıp ç sesini türetmiştir. Kalenin adının Osmanlı alfabesi ile de yazılışı ç harfiyledir.

Kısacası bu kalenin adı Çift - Kale'dir ve Cufutlukla da Yahudilikle de bir ilgisi yoktur.

\section{KAYNAKLAR}

Altınkaynak, Erdoğan, "Kırım Karaylarının Kutsal Mekanı Balta Tiymez Mezarlığı Ormanı ve MezarlığaYapılan Saldırılar", Türk Dünyası Tarih Dergisi, 208, İstanbul 2004.

Altınkaynak, Erdoğan, Tozlu Zaman Perdesinde Kırım Karayları, Haarlem 2006.

Anzerlioğlu, Yonca, Karamanlı Ortodoks Türkler, Ankara 2003.

Evliya Çelebi Seyahatnamesi, (Sadeleştirenler: Tevfik Temelkuran - Necati Aktaş - Mümin Çevik) VIII, İstanbul 1980.

Kuzgun, Şaban, Hazar ve Karay Türkleri, Ankara 1993.

Ortaylı, İlber, Osmanlı'da Milletler ve Diplomasi, İstanbul 2008.

Szapszal, Seraya, 'Staroturatskıy przyrostek ur zachowany gdzie niegdzie we wspolczesnej mowie potoczej'- Rocznik Orientalistyczny, Lvov. 1938, 81-90 